\title{
Helminths Parasites in Small and Large Ruminants at Sohag Governorate, Egypt: Prevalence and Seasonal Dynamics
}

\section{Mahmoud A. Elseify', Nagwa G. Abd Alrahman², Khaled Sultan', Amer R. Abdel Aziz ${ }^{2}$}

${ }^{1}$ Department of Parasitology, Faculty of Veterinary Medicine, Kafrelsheikh University, Egypt, ${ }^{2}$ Department of Parasitology, Faculty of Veterinary Medicine, Sohag University, Egypt.

\section{Abstract}

Prevalence and seasonal variations of some helminth parasites was conducted in (cattle, buffaloes, sheep, and goats) from Sohag Governorate, Egypt with overall prevalence (44.64\%). Infection rate was in cattle $(52.78 \%)$, in buffaloes $(48.84 \%)$, in sheep $(34.32 \%)$ and in goats $(27.27 \%)$. Fasciola spp. was higher in sheep (6.51\%) while the lowest infection rate was in goats (3.64\%). For Paramphistomum spp., the highest infection rate was in buffaloes $(1.7 \%)$ and the lowest was in cattle $(0.8 \%)$. For Moniezia spp. sheep had the highest infection rate $(22.49 \%)$ while the lowest infection rate was in buffaloes (19.2\%). For Toxocara vitulorum, cattle had the highest infection rate $(31.4 \%)$ while the lowest was in buffaloes (26.8\%). In addition, for Strongyle type eggs, the highest infection rate was in cattle $(8.1 \%)$ while the lowest was in goats $(1.8 \%)$. For Strongyloides spp. eggs prevalence rates in cattle and sheep were $(0.8 \%)$ and $(0.6 \%)$ respectively. Trichuris spp. eggs were found only in sheep with an infection rate $(0.6 \%)$. Significantly cattle and buffaloes at age $>3 y$ were the highly infected group, but for sheep and goat, age group at age 1-3y were the highly infected group. Seasonally, winter was significantly with highest infection rate in both cattle and sheep, but summer season was significantly with highest infection rate in buffaloes and goats. Strongyle type eggs were cultured to detect several larvae including (110 cattle, 59 buffaloes, and 56 sheep) and the following larvae were detected (Oesophagostomum radiatum, Cooperia onchophora Trichostrongylus axei, Ostertagia ostertagi, Cooperia curticei, Ostertagia circumcincta, and Haemonchus contortus).

Keywords:

Helminths, Prevalence, Ruminants, Seasonal dynamics, Sohag.

DOI: 10.21608/svu.2021.93862.1147 Received: September 1, 2021 Accepted: December 15, 2021 Published: December 31, 2021

*Corresponding Author: Nagwa G. Abd Alrahman E-mail: nagwagamal798@yahoo.com Citation: Elseify et al., Helminths Parasites in Small and Large Ruminants at Sohag Governorate, Egypt: Prevalence and Seasonal Dynamics. SVU-IJVS 2021, 4 (4): 85-100.

Copyright: (C) Elseify et al. This is an open access article distributed under the terms of the creative common attribution license, which permits unrestricted use, distribution and reproduction in any medium provided the original author and source are created.

Competing interest: The authors have declared that no competing interest exists. 


\section{Introduction}

Heavy helminth parasites infection causes a reduction in productivity of animal. In cattle and buffaloes, parasitism causes decrease in milk yield interfering with physiological digestion leading to malabsorption of basic minerals essential for milk production in mammary gland e.g., calcium and important vitamins, while in sheep and goats it limits the absorption of essential amino acids that are important for wool and hair, causing a reduction in quality and yield (Murthy and Rao, 2014).

Ruminants harbor large number of nematodes; some of them causing a harmful effect that may lead to death. The majority belong to the family Trichostrongylidae which embraces most of the nematodes of highly economic and pathogenic effects. It is important to identify the helminth species and the level of infection that causes the pathogenic effect in purpose to provide proper management of them (Jurasek et al., 2010).

Several studies were limited on the prevalence of helminth parasites in different areas at Egypt including studies by (Sultan et al., 2010) in Mid-Delta, (Khalafalla et al., 2011) in El-Mahalla El-Kubra City, ( Hamed et al., 2013) in Assiut, (ELshahawy et al., 2014) in Aswan, (Elbahy et al., 2015) in Sadat city and (Hassan et al., 2019) in Giza. To our knowledge, few studies were done on the prevalence and seasonal dynamics of helminth parasites that infect small and large ruminants at Sohag Governorate. Therefore, the aim of the present study was to determine the most prevalent helminth parasites through the identification of recovered species and seasonal dynamics of helminths eggs and larvae by sedimentation, flotation, and coproculture techniques.

\section{Material and Methods Ethical approval:}

This study was reviewed and approved by the ethics committee of the Medical Research Institute (MRI), Sohag University, October 2015.

\section{Study area and sample collection:}

The present study was conducted during the period from July 2019 to June 2020 in Sohag Governorate $\left(26^{\circ} 33^{\prime} \mathrm{N} \quad 31^{\circ} 42^{\prime} \mathrm{E}\right)$ which located in Upper Egypt. Sohag province has a desert climate as in Fig. 1. and several districts were such as Akhmium, Sohag city, El-Maragha, Tema, and Tahta.

A total of 811 fecal samples from cattle, buffaloes, sheep, and goats were collected directly from the rectum or freshly defecated samples in plastic bottles, then labeled with species, sex, age, date and locality and send to the Parasitology lab at the Faculty of Veterinary medicine, Sohag University. Fecal samples were divided into 2 groups; the first group was incubated for coproculture and the second group was stored at $4^{\circ} \mathrm{C}$ for direct fecal examination by sedimentation and flotation techniques.

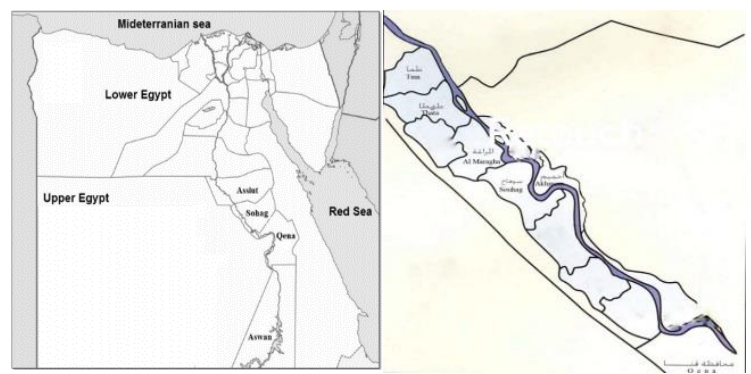

Fig. 1. Different districts of the study area in Sohag Governorate represented in Egypt map.

\section{Fecal examination}

Stored samples were examined via sedimentation technique and flotation technique by using of saturated salt solution (specific gravity 1.020) then the samples were centrifuged at $1500 \mathrm{rpm}$ for $5 \mathrm{~min}$, then examined by $(\mathrm{x} 40)$ as mentioned by (Hossain et al., 2011). 
Coproculture examination of Strongyle type eggs:

A total of 225 Fecal cultures (110 cattle, 59 buffaloes, and 56 sheep) were done to distinguish the larvae of Strongyle type eggs and revealed detected larvae according to van Wyk et al., (2004) and the identification of detected larvae was performed according to keys by van Wyk and Mayhaw, (2013).

\section{Statistical analysis:}

The collected data in the present study were introduced into Excel spreadsheets (Windows 2010) and statistically analyzed using IBM SPSS statistics software, version 22. (Chicago, IL). According to the data distribution, descriptive data was reported as means (M) with standard deviations and ranges. Frequency distributions were used to characterize categorical variables. The Chisquare test was employed. A $P$ values of < 0.05 was significant while $P$ values of $<0.01$ was highly significant.

\section{Results}

The recovered eggs of helminth parasites in different examined animal species, were displayed in Table 1, where the rate of infection with Fasciola spp. was $(5.83 \%),(6.40 \%),(6.51 \%)$ and $(3.64 \%)$ in cattle, buffaloes, sheep, and goats respectively. For Paramphistomum spp., the infection rate was higher in buffaloes $(1.7 \%)$ followed by sheep $(1.2 \%)$ then cattle with overall prevalence $(0.8 \%$; table 1$)$. The infection rate of Moniezia spp. was (20.3\%), (19.2), (22.49\%) and (20.9\%) in cattle, buffaloes, sheep, and goats respectively (Table 1). For Toxocara Vitulorum, the infection rate of T.vitulorum in cattle was higher $(31.4 \%)$ than buffaloes $(26.8 \%$; table1). The infection rate of Strongyle type eggs was $(8.1 \%),(6.4 \%),(6.5 \%)$ and $(1.8 \%)$ in cattle, buffaloes, sheep, and goats respectively (table 1). For Strongyloides spp. eggs infection with Strongyloides spp. was only in cattle and sheep and the infection rate was $(0.8 \%)$ and $(0.6 \%)$ respectively (table 1). Sheep were only infected with Trichuris ovis; with overall prevalence of $(0.6 \%$; Table1).

The highest infection rate of helminth parasites in different examined animals was in cattle $(52.78 \%)$ followed by buffaloes $(48.84 \%)$ then sheep $(34.32 \%)$, the lowest was in goats (27.27\%) (Table 1, Fig. 2).

Table 1. Prevalence of different helminth parasites in cattle and buffaloes:

\begin{tabular}{|c|c|c|c|c|c|c|c|c|}
\hline \multirow[t]{2}{*}{ Parasitic infection } & \multicolumn{2}{|c|}{$\begin{array}{c}\text { Cattle } \\
\text { Ex.=360 } \\
\text { P }=(\mathbf{5 2 . 7 8 \%}) \\
\text { Positive }\end{array}$} & \multicolumn{2}{|c|}{$\begin{array}{c}\begin{array}{c}\text { Buffaloes } \\
\text { Ex. }=172 \\
P=(48.84 \%)\end{array} \\
\text { Positive }\end{array}$} & \multicolumn{2}{|c|}{$\begin{array}{c}\text { Sheep } \\
\text { Ex.=169 } \\
\text { P=(34.32\%) } \\
\text { Positive }\end{array}$} & \multicolumn{2}{|c|}{$\begin{array}{c}\text { Goats } \\
\text { Ex.=110 } \\
\begin{array}{c}\text { P=(27.27\% }) \\
\text { Positive }\end{array}\end{array}$} \\
\hline & $(\mathbf{N})$ & $(\%)$ & $(\mathbf{N})$ & $(\%)$ & $(\mathbf{N})$ & $(\%)$ & 4 & 3.64 \\
\hline Fasciola spp. & 21 & 5.83 & 11 & 6.40 & 11 & 6.51 & 0 & 0.00 \\
\hline Paramphistomum spp. & 3 & 0.8 & 3 & 1.7 & 2 & 1.2 & 23 & 20.9 \\
\hline Monezia spp. & 73 & 20.3 & 33 & 19.2 & 38 & 22.49 & 2 & 1.8 \\
\hline Toxocara vitulorum & 113 & 31.4 & 46 & 26.8 & 0 & 0 & 0 & 0 \\
\hline Strongyloides spp. & 3 & 0.8 & 0 & 0 & 1 & 0.6 & 0 & 0 \\
\hline Trichuris ovis & 0 & 0 & 0 & 0 & 1 & 0.6 & 0 & 0 \\
\hline Strongyle type eggs & 29 & 8.1 & 11 & 6.4 & 11 & 6.5 & 2 & 1.8 \\
\hline
\end{tabular}

Concerning the sex of different animal species, female cattle were highly infected $(53.01 \%)$ than males $(52.25 \%)$. In buffaloes, females were highly infected $(51.09 \%)$ than males (40\%). On the other hand, male sheep had a higher infection rate $(36.59 \%)$ than females $(33.59 \%)$, while in goats, females had high infection rate $(27.78 \%)$ than males (25.64\%; Table 2). 
Table 2. Overall prevalence of helminth parasites in relation to sex of cattle:

\begin{tabular}{|c|c|c|c|c|c|}
\hline \multirow{2}{*}{\multicolumn{2}{|c|}{ Sex }} & \multirow{3}{*}{$\begin{array}{c}\text { Total } \\
\text { Ex. } \\
111\end{array}$} & \multicolumn{2}{|c|}{ Positive } & \multirow[t]{3}{*}{$P$ value } \\
\hline & & & $\mathbf{N}$ & $\%$ & \\
\hline \multirow{3}{*}{ Cattle } & Male & & 58 & 52.25 & \\
\hline & Female & 249 & 132 & 53.01 & \multirow{2}{*}{0.874} \\
\hline & Total & 360 & 190 & 51.49 & \\
\hline \multirow{3}{*}{ Buffaloes } & Male & 35 & 14 & 40.00 & \multirow{3}{*}{0.241} \\
\hline & Female & 137 & 70 & 51.09 & \\
\hline & Total & 172 & 84 & 48.84 & \\
\hline \multirow{3}{*}{ Sheep } & Male & 41 & 15 & 36.59 & \multirow{3}{*}{0.725} \\
\hline & Female & 128 & 43 & 33.59 & \\
\hline & Total & 169 & 58 & 34.32 & \\
\hline \multirow{3}{*}{ Goats } & Male & 39 & 10 & 25.64 & \multirow{3}{*}{0.692} \\
\hline & Female & 72 & 20 & 27.78 & \\
\hline & Total & 111 & 30 & 27.27 & \\
\hline
\end{tabular}

Fig. 2. Eggs of parasites by (x40). (a) Egg of Fasciola spp., (b) Egg of

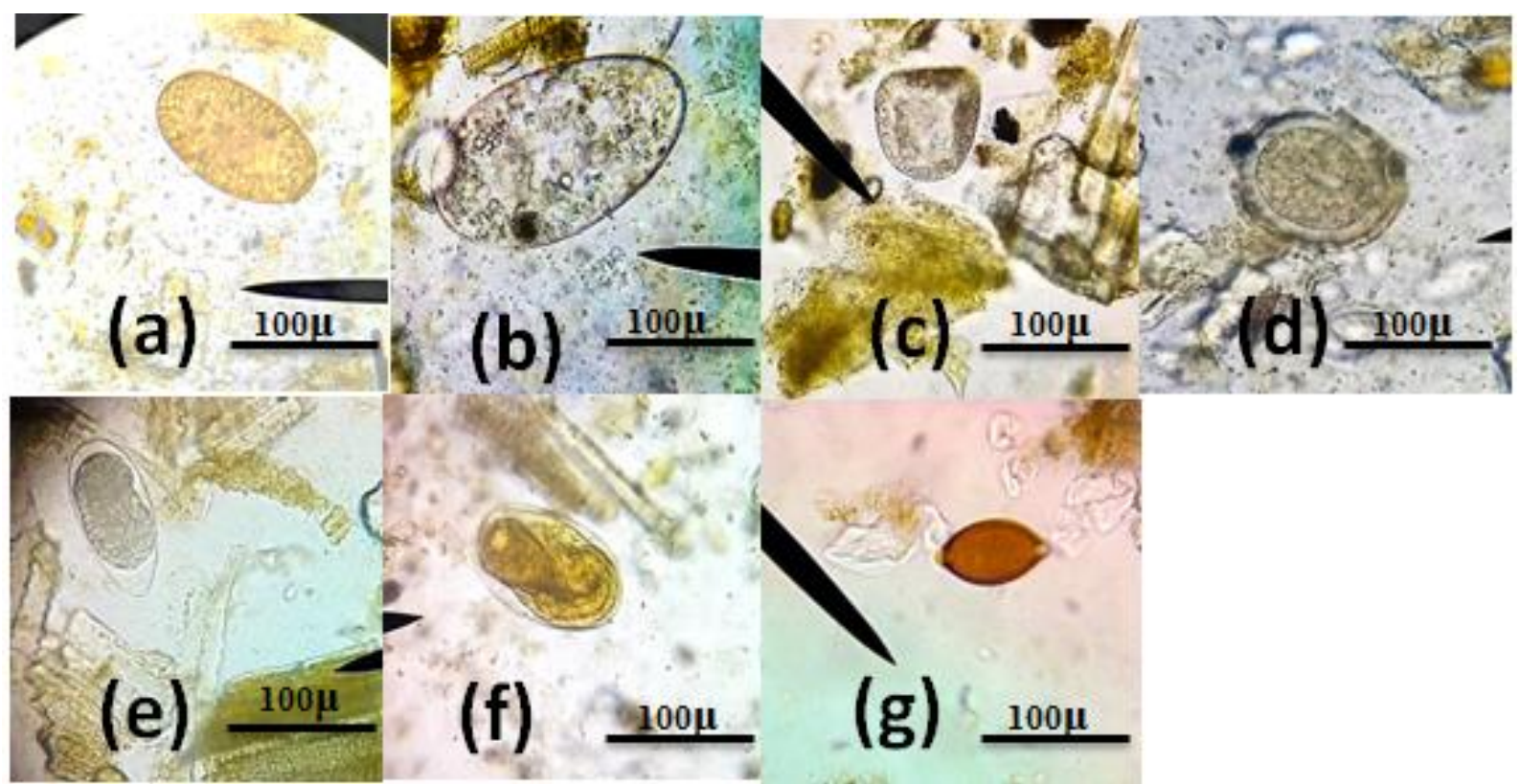

Paramphistomatidae spp, (c) Egg of Moniezia spp. (d) Egg of T.vitulorum, (e) Egg of Strongylus spp., (f) Egg of Strongyloides spp., (g) Egg of Trichuris ovis.

For age groups, cattle at age $>3 y$ were significantly had the highest infection rate $(37.37 \%)$ followed by cattle at age $0-1 y$ $(32.63 \%)$ and the lowest infection rate was in animals at age 1-3y (30\%). In buffaloes, the highest rate of infection was in animals at age $>3 y(48.81 \%)$ followed by animals at age $0-1 y(30.95 \%)$, and finally animals at age $1-3 y(20.24 \%)$. In sheep, animals at age $1-3 y$ had the highest percentage of infection $(51.52 \%)$ followed by animals at age $0-1 y$ $(40 \%)$ and the lowest infection rate was in animals at age $>3 y(6.67 \%)$.In goats, animals at age (0-1y) and (1-3y) had the same infection rate $(46.67 \%)$ and the lowest infection rate was in animals at age $>3 y$ $(6.67 \%)$ (Table 3). 
Table 3. Prevalence of helminth parasite infection in different animal species in relation to age:

\begin{tabular}{|c|c|c|c|c|c|c|c|c|}
\hline \multirow{3}{*}{ Species } & \multicolumn{7}{|c|}{ Age } & \multirow{3}{*}{$P$ value } \\
\hline & \multirow{2}{*}{$\begin{array}{c}\text { Total } \\
\text { (P) }\end{array}$} & \multicolumn{2}{|c|}{$(0-1)$} & \multicolumn{2}{|c|}{ (1-3) } & \multicolumn{2}{|c|}{$(>\mathbf{3})$} & \\
\hline & & $\mathbf{P}(\mathbf{N})$ & $\mathbf{P}(\%)$ & $\mathbf{P}(\mathbf{N})$ & $\mathbf{P}(\%)$ & $\mathbf{P}(\mathbf{N})$ & $\mathbf{P}(\%)$ & \\
\hline Cattle & 190 & 62 & 32.63 & 57 & 30.00 & 71 & 37.37 & \\
\hline Buffaloes & 84 & 26 & 30.95 & 17 & 20.24 & 41 & 48.81 & 50001 \\
\hline Sheep & 58 & 24 & 40.00 & 30 & 51.52 & 4 & 6.67 & $<0.0001$ \\
\hline Goats & 30 & 14 & 46.67 & 14 & 46.67 & 2 & 6.67 & \\
\hline
\end{tabular}

**: Difference highly significant when $(\mathrm{P}<0.01)$.

Seasonal prevalence of recovered eggs in different animal species showed that the winter season was significantly had the highest infection rate in cattle $(67.90 \%)$ followed by Autumn (65.22\%) then spring $(43.59 \%)$, the lowest infection rate was recorded in the summer season $(37.61 \%)$, but in buffaloes, summer season was significantly had the highest infection rate $(60.78 \%)$ followed by winter $(53.19 \%)$ then spring season $(44.44 \%)$ and the lowest infection rate was in autumn season (31.58\%).
P: Positive

On the other hand, in sheep, the highest significant infection rate was in the winter season $(63.16 \%)$ followed by spring $(32.50 \%)$ then autumn $(23.08 \%)$, while the lowest infection rate was observed in the summer season was significant of high infection rate $(23.07 \%)$, but in goats, summer $(32.56 \%)$ followed by autumn $(26.67 \%)$ then spring $(25.81 \%)$, while winter season had the lowest infection rate $(19.05 \%)$ (Table 4)

Table 4. Prevalence of helminth parasite infection in cattle and buffaloes in relation to season:

\begin{tabular}{|c|c|c|c|c|c|c|c|c|c|c|c|c|}
\hline \multirow{3}{*}{ Seasons } & \multicolumn{3}{|c|}{ Cattle } & \multicolumn{3}{|c|}{ Buffaloes } & \multicolumn{3}{|c|}{ Sheep } & \multicolumn{3}{|c|}{ Goats } \\
\hline & \multirow{2}{*}{$\begin{array}{c}\text { Total } \\
\text { Ex. }\end{array}$} & \multicolumn{2}{|c|}{ Positive } & \multirow{2}{*}{$\begin{array}{c}\text { Total } \\
\text { Ex. }\end{array}$} & \multicolumn{2}{|c|}{ Positive } & \multirow{2}{*}{$\begin{array}{c}\text { Total } \\
\text { Ex. }\end{array}$} & \multicolumn{2}{|c|}{ Positive } & \multirow{2}{*}{$\begin{array}{c}\text { Total } \\
\text { Ex. }\end{array}$} & \multicolumn{2}{|c|}{ Positive } \\
\hline & & $\mathbf{N}$ & $\%$ & & $\mathbf{N}$ & $\%$ & & $\mathbf{N}$ & $\%$ & & $\mathbf{N}$ & $\%$ \\
\hline Summer & 109 & 41 & 37.61 & 51 & 31 & 60.78 & 54 & 12 & 23.07 & 43 & 14 & 32.56 \\
\hline Autumn & 92 & 60 & 65.22 & 38 & 12 & 31.58 & 39 & 9 & 23.08 & 15 & 4 & 26.67 \\
\hline Winter & 81 & 55 & 67.90 & 47 & 25 & 53.19 & 36 & 24 & 63.16 & 21 & 4 & 19.05 \\
\hline Spring & 78 & 34 & 43.59 & 36 & 16 & 44.44 & 40 & 13 & 32.50 & 31 & 8 & 25.81 \\
\hline$P$ value & & & $<0.0001$ & & & $0.044^{*}$ & & & $0.0001 * *$ & & & 0.715 \\
\hline
\end{tabular}

**: Difference highly significant $(\mathrm{P}<0.01)$. *: Difference significant $(\mathrm{P}<0.05)$.

For the prevalence of Strongylus larvae, cattle was significantly had the highest infection rate with nematode larvae $(7.27 \%)$ followed by sheep $(5.36 \%)$ and the lowest infection rate was in buffaloes $(3.39 \%)$, The detected larvae in cattle was Oesophagostomum radiatum (2.72\%), Cooperia onchophora (1.8\%),
Trichostrongylus axei(1.8\%) and Ostertagia ostertagi $(0.9 \%)$. In buffaloes, the obtained larvae were Oesophagostomum radiatum $(1.69 \%)$ and Ostertagia ostertagi (1.69\%). In sheep, the detected larvae were Cooperia curticei (1.79\%), Ostertagia circumcincta (1.79\%), and Haemonchus contortus (1.79\%) (Table 5, Fig. 3). 
Elseify et al., 2021

Table 5. Prevalence of larvae after fecal culture of Strongyle spp. eggs:

\begin{tabular}{|c|c|c|c|c|c|c|c|}
\hline \multirow[t]{2}{*}{ Larvae } & \multicolumn{2}{|c|}{$\begin{array}{l}\text { Cattle } \\
\text { Ex.=110 } \\
\text { Positive }\end{array}$} & \multicolumn{2}{|c|}{\begin{tabular}{|c|} 
Buffaloes \\
Ex.=59 \\
Positive
\end{tabular}} & \multicolumn{2}{|c|}{\begin{tabular}{|l|} 
Sheep \\
Ex.=56 \\
Positive
\end{tabular}} & \multirow[t]{2}{*}{$P$ value } \\
\hline & $(\mathbf{N})$ & $(\%)$ & $(\mathbf{N})$ & $(\%)$ & $(\mathbf{N})$ & $(\%)$ & \\
\hline O. radiatum & 3 & 2.72 & 1 & 1.69 & 0 & 0 & \multirow{8}{*}{$0.0175^{*}$} \\
\hline C. onchophora & 2 & 1.8 & 0 & 0 & 0 & 0 & \\
\hline Cooperia curticei & 0 & 0 & 0 & 0 & 1 & 1.79 & \\
\hline T. axei & 2 & 1.8 & 0 & 0 & 0 & 0 & \\
\hline O. ostertagi & 1 & 0.9 & 1 & 1.69 & 0 & 0 & \\
\hline T. circumcincta & 0 & 0 & 0 & 0 & 1 & 1.79 & \\
\hline H. contortus & 0 & 0 & 0 & 0 & 1 & 1.79 & \\
\hline Total & 8 & 7.27 & 2 & 3.39 & 3 & 5.36 & \\
\hline
\end{tabular}

*: Difference significant $(\mathrm{P}<0.05)$

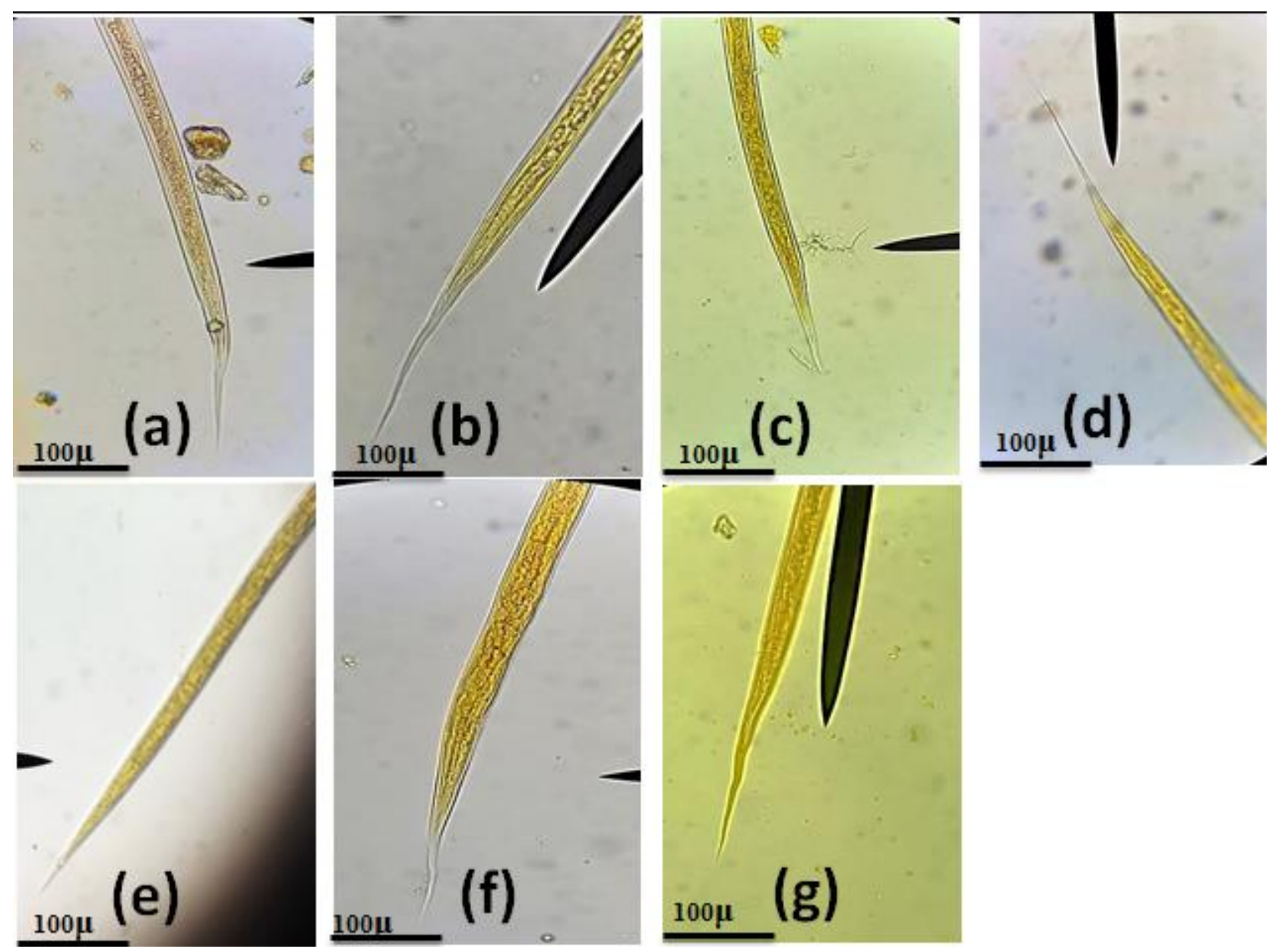

Fig. 3. Tail end of Strongyle larvae by (x40). (a) Cooperia curticei (b) Haemonchus contortus (c) Ostertagia circumcincta (d) Oesophagostomum radiatum (e) Trichostrongylus axei (f) Ostertagia ostertagi (g) Cooperia onchophora. 


\section{Discussion}

In the current study, the overall prevalence of Fasciola spp. in cattle was $(5.83 \%)$, of no significant difference ( $p>$ $0.05)$. These findings are lower than the previous reports by Ntonifor et al., (2013) in Cameroon and Kuraa and Malek, (2014) in Egypt who found that the infection rate of Fasciola spp. is $(6.1 \%)$ and $(8 \%)$ respectively. On the other hand, the present study is higher than previous findings by Maharana et al., (2016) and Bharathi and Kumar, (2017) in India who found that the infection rate of Fasciola spp. was (1.66\%) and $(4.41 \%)$ respectively. In buffaloes, the infection rate of Fasciola spp. in the current study is $(6.40 \%)$, no significant difference ( $p>0.05$ ). The current study is lower than the report by Hossain et al., (2011) in Bangladesh who found that the infection rate was $(10 \%)$. In contrast, the present observations are higher than those results in India by Nath et al., (2016), Yadav et al., (2019), and Jas et al., (2020) which revealed that the total infection rate of Fasciola spp. was $(2.30 \%), \quad(5.31 \%)$ and $(5 \%)$ respectively. In sheep, infection rate of Fasciola spp. was (6.51\%), no significant difference ( $p>0.05$ ). The current work is lower than studies in Ethiopia by Negasi et al., (2012), Ibrahim et al., (2014), and Elemo and Geresu, (2017) who found that the infection rate was $(28.14 \%),(19.6 \%)$, and (7.2\%) respectively, but the present study is higher than previous findings in Ethiopia by Ayana and Ifa, (2015) and Chala et al., (2019) who stated that the infection rate of Fasciola spp. in fecal samples was $(4.4 \%)$ and $(6 \%)$ respectively. The infection rate in goats in the current study was (3.64\%), of no significant difference ( $p>0.05)$. These findings are lower than studies by Lone et al., (2012) in India, Ibrahim et al., (2014) in Ethiopia, and Sunday et al., (2020) in Nigeria who found that the infection rate of Fasciola spp. in fecal samples was (30.65\%), (7.6\%), and (15.32\%) respectively. The present work is higher than studies by Hassan et al., (2013) in Egypt and Chala et al., (2019) in Ethiopia who found that the infection rate was $(2.67 \%)$ and $(2.3 \%)$ respectively. These results may be attributed to the fact that most of the food delivered for animals in our country depends on green grass which increases contact between animals and encysted metacercaria of Fasciola spp., also geographical differences and variation in diet affect infection rate.

In the present study the overall prevalence of Paramphistomum spp. was in cattle $(0.8 \%),(1.7 \%)$, and $(1.2 \%)$ in cattle, buffaloes, and sheep respectively. Results showed that no infection with Paramphistomum spp. in goats, statistically results of no significant importance ( $\mathrm{p}>$ $0.05)$. These results in cattle are lower than previous studies in India by Haque et al., (2012), Maharana et al., (2016), and Marskole et al., (2016) who reported that the infection rate was $(1.44 \%),(1.99 \%)$ and (5.27\%) also Aragaw and Tilahun, (2019) in Ethiopia found that the infection rate was (48.5\%). In buffaloes, the current study is higher than the report by Haque et al., (2012) in India who reported that the infection rate was $(1.12 \%)$. On the other hand, the current study is lower than studies by Maharana et al., (2016) and Marskole et al., (2016) in India who reported that the infection rate was $(3.51 \%)$ and $(4.55 \%)$ respectively. In sheep, these findings are higher than the report by Ploeger et al., (2017) in the Netherlands who found that the infection rate was $(0.2 \%)$. The current study is lower than previous findings by Sultan et al., (2016) in Egypt who found that the infection rate was $(9.3 \%)$, Negasi et al., (2012), and Ibrahim et al., (2014) in Ethiopia who stated that the infection rate was $(14.81 \%)$ and $(22.4 \%)$ respectively. The lower percentage of infection might be due to the proper eradication system for intermediate host responsible for infection with Paramphistomum spp. 
The overall prevalence of Moniezia spp. in the current study in cattle is (20.3\%), statistically non-significant ( $p>0.05$ ). The present study is higher than the study by Marskole et al., (2016) and Bharathi and Kumar et al., (2017) in India who observed that the infection rate was $(7.90 \%)$ and $(1.47 \%)$ respectively. In buffaloes, infection rate of Monezia spp. is (19.2\%), of no significant importance ( $>$ $>0.05$ ). The present findings are higher than previous studies by Marskole et al., (2016) and Jas et al., (2020) in India who observed that the infection rate was $(6.82 \%)$ and $(3.50 \%)$ respectively. In sheep, the current findings showed that infection rate of Moniezia spp. is $(22.49 \%)$, of no significant importance ( $>$ > 0.05). The current study is lower than Lone et al., (2012) in India who found that the infection rate was $(29.01 \%)$, but the present study is higher than Ibrahim et al., (2014) in Ethiopia and Sultan et al., (2016) in Egypt who found that the infection rate was $(13.1 \%)$ and $(0.89 \%)$ respectively. In goats, the infection rate of M.expansa is (20.9\%), of no significant importance ( $p>$ 0.05). These findings are lower than Aliyu et al., (2020) in Nigeria who found that the infection rate was $(29.4 \%)$, but the present study is higher than reports by Lone et al., (2012) in India who stated that the infection rate was (18.90\%) and Negasi et al., (2012) in Ethiopia who found that the infection rate was $(15.09 \%)$. The highest infection rate in the present study with cestodes might be due to the favorable environmental condition, availability of intermediate host, low hygiene, and low knowledge of farmers about the importance of deworming against Moniezia spp.

In the current results, the infection rate of T.vitulorum in cattle was $(31.4 \%)$, while in buffaloes was $(26.8 \%)$, of no significant importance $(p>0.05)$. The present study in cattle is lower than studies by Raza et al., (2010) in Pakistan, Awraris et al., (2012) who observed that the infection rate of T.vitulorum was $(37.50 \%)$ and (57\%) respectively. On the other hand, results by Raza et al., (2013) showed that the infection rate was $(15 \%)$ and Bharathi and Kumar, (2017) revealed that the infection rate was $(16.17 \%)$, which lower than the present study. In buffaloes, the infection rate of T.vitulorum was lower than the previous report by Raza et al., (2010) in Pakistan who reported that the infection rate was $(63.83 \%)$. The present study is higher than the report by Maharana et al., (2016) in India who observed that the infection rate of T.vitulorum was $(5.26 \%)$ and reports in Pakistan by Zaman et al., (2014) and Deeba et al., (2019) who found that the infection rate of T.vitulorum was $(17.75 \%)$ and $(13.93 \%)$ respectively. The variations between the present study and other studies are attributed to variations in sample size, climatic conditions. breed, sex, and age of animals.

In the current study, the infection rate of Strongyle spp. was $(8.1 \%),(6.4 \%),(6.5 \%)$ and $(1.8 \%)$ in cattle, buffaloes, sheep, and goats respectively, of no statistically significant importance ( $p>0.05)$. In cattle, the infection rate is lower than previous reports by Awraris et al., (2012) in Ethiopia, Ntonifor et al., (2013) in Cameroon, Tulu and Lelisa, (2016) in Ethiopia, Maharana et al., (2016) in India who observed that the infection rate was $(56.07 \%)$, $(55.8 \%)$, $(36,32 \%)$ and $(8.29 \%)$ respectively, but the present study is higher than the previous study by Kumar et al., (2016) in India who found that the infection rate was $(4.5 \%)$.In buffaloes, the present study is lower than studies by Nath et al., (2016) and Marskole et al., (2016) in India who found that the infection rate was $(25.59 \%)$ and $(47.37 \%)$ respectively. On the other hand, the infection rate in the present study was higher than Kumar et al., (2016) and Maharana et al., (2016) in India who observed that the infection rate was $(2.8 \%)$ and $(3.51 \%)$ respectively. The difference might be due to variation in the rearing system, temperature, humidity, presence, or absence of rain. In 
sheep, the present study is lower than reports by Tramboo et al., (2015) in India with an overall prevalence $(57.75 \%)$, Kakar et al., (2013) in Pakistan who found the infection rate was $(58.94 \%)$, and Chikweto et al., (2018) in west indies who found the infection rate was $(75 \%)$. In goats, the current study is lower than Ntonifor et al., (2013) in Cameroon who found that the infection rate was $(55.8 \%)$ and studies in Ethiopia by Ibrahim et al., (2014) and Elemo and Geresu, (2017) who found that the infection rate was $(23.5 \%),(53.33 \%)$ respectively and Hassan et al., (2019) in Egypt who observed that the infection rate was $(25.71 \%)$ The lower infection rate in the present study in both sheep and goats than other studies might be due to low exposure of animals to grazing which considered a common method for the rearing of small ruminants in other countries and these make animals most exposed to parasitic infestation, also the temperature difference, hygiene might play a role in variations.

In the current study, the overall prevalence of Strongyloides spp. in cattle was $(0.83 \%)$, of no significant importance ( $>$ 0.05). The present study is lower than studies in Nigeria by Adedipe et al., (2014) and Yohanna et al., (2019) who found that the infection rate was $(4.86 \%)$ and $(1.46 \%)$ respectively, and reports by Rashid et al., (2015) in Bangladesh and Tulu and Lelisa, (2016) in Ethiopia who observed that the infection rate was $(7.39 \%)$ and $(6.54 \%)$ respectively. In sheep, the infection rate of Strongyloides spp. was $(0.6 \%)$, of no significant importance ( $>$ 0.05). The present study is lower than Rashid et al., (2016) in Pakistan and Sunday et al., (2020) in Nigeria who stated that the infection rate was $(17.3 \%)$ and $(16.04 \%)$ respectively. The low infection rate with Strongyloides spp. might be due to unfavorable climatic conditions that enhance survival and development of the larval stage.
The overall prevalence of Trichuris ovis in sheep in the present study was $(0.6 \%)$, with no significant difference ( $p>0.05)$. The current results are lower than previous studies by Khalafalla et al., (2011) and Sultan et al., (2016) in Egypt, who noticed that the infection rate was (5.8\%) and $(2.68 \%)$ respectively, and studies by Ibrahim et al., (2014) and Chala et al., (2019) in Ethiopia who observed that the infection rate was $(7.9 \%)$ and $(1.9 \%)$ respectively. The low infection rate in the present study might be due to unfavorable environmental conditions for the development of the larval stage.

In the current study, the infection rate was $(52.8 \%),(48.84 \%),(34.32 \%)$ and $(27.27 \%)$ in cattle, buffaloes, sheep, and goats respectively, the difference between species of highly significant importance $(p<0.01)$. This result in cattle is relatively higher than studies by and Raza et al., (2013) from Pakistan and Tulu and Lelisa, (2016) from Ethiopia with an infection rate ( $51 \%$ ) and $(50.08 \%)$ respectively, but the current findings were lower than the infection rate by Ntonifor et al., (2013) in Cameroon who found that the infection rate was ( $56.7 \%)$, $(64 \%)$ in Bangladesh by Chowdhury et al., (2017) and $(74.3 \%)$ in Nigeria by Umar et al., (2018). Current findings in buffaloes are low in compared to the infection rate $(54.47 \%)$ by Deeba et al., (2019) in Pakistan, $(64.67 \%)$ in India by Patel et al., (2015), and $(85.01 \%)$ in Bangladesh by Alam et al., (2016), but the present study is higher than studies by Saha et al., (2013) in India and Ahmad et al., (2020) in Bangladesh with an overall prevalence $(39.6 \%)$ and $(36.47 \%)$ respectively. The present study in sheep is low in compare to the infection rate $(51.9 \%)$ in Mid-Delta, Egypt by Sultan et al., (2010), $(56.25 \%)$ in Northern Ethiopia by Negasi et al., (2012), and $(73.1 \%)$ in Cameroon by Ntonifor et al., (2013), but the present findings are higher than a study by Yohanna et al., (2019) in Nigeria who found that the infection rate was $(33.7 \%)$. Current findings 
in goats are lower than the study by Negasi et al., (2012) who reported an infection rate of $(35.33 \%)$ in goats of Northern Ethiopia, Anugrah et al., (2018) in India who reported an infection rate of $(58.4 \%)$ in goats, and Sutar et al., (2010) who reported an infection rate of $(62.75 \%)$ in goats of Ahmednagar in India, on the other hand, the present study is higher than studies by ElKhtam and Khalafalla,( 2016) and ELshahawy et al., (2014) from Egypt who reported a total prevalence of $(23.54 \%)$ and $(24.44 \%)$ respectively. These variations between the present study and the previous studies contributed to the differences in geographical districts, breed of animals, grazing and feed habits, rearing habits of animals from one district to another, knowledge of farmers about medication against helminth parasites, and to what extent intermediate hosts are available.

Concerning sex, the infection rate of helminth parasites in cattle in the present study revealed that females had high infection rate than males but of no significant difference $(p>0.05)$. These findings in cattle agree with previous findings by Rashid et al., (2015) in Bangladesh and Maharana et al., (2016) in India who reported that females were highly infected than males. On the other hand, these findings contrast with the previous studies by Raza et al., (2013) in Pakistan, Marskole et al., (2016) in India, Tulu and Lelisa, (2016) in Ethiopia who reported that males were highly infected than females. Also in buffaloes and goats, the present study revealed that female animals were highly infected than males, but of no significant importance $(p>0.05)$. These results in buffaloes are in agreement with studies by Maharana et al., (2016) in India and Alam et al., (2016) in Bangladesh who reported that females were highly infected than males. Moreover, these results disagree with previous studies by Zaman et al., (2014) in Pakistan, Marskole et al., (2016) in India who reported that males were highly infected than females. In goats, the present study agrees with Admasu and Nurlign, (2014) in Ethiopia and Anugrah et al., (2018) in India who reported that females were highly infected than males, but current findings are dissimilar from previous studies by Yohanna et al., (2019) in Nigeria, who reported that males were highly infected than females. These findings in the current study might be due to stress factors which females are exposed to as pregnancy and lactation, besides hormonal imbalance which affects immunity of females, also breeds of animals might play a role in variation. In sheep, the present study revealed that males had high infection rate than females but of no significant difference $(p>0.05)$. The present study agrees with studies conducted by Eke et al., (2019) and Yohanna et al., (2019) in Nigeria, who reported that males were highly infected than females, but different from studies performed by Negasi et al., (2012) and Chala et al., (2019) in Ethiopia who reported that females were highly infected than males. These findings agree with opinions that suggest that the high infection rate in males due to hormonal effects as androgens inhibit the immune system of animals also feeding habits in males lead to the high exposure of males to parasitic infection.

Prevalence of helminth parasites about age in the current study showed that in cattle and buffaloes, the highest infection rate of infection was in animals (>3y), of highly significant difference $(\mathrm{p}<0.01)$. A similar observation in cattle was detected by Yohanna et al., (2019) in Nigeria who found that adult cattle were highly infected than young. On the other hand, these findings contrast with reports by Umar et al., (2018) in Nigeria who reported that young animals were highly infected than other age groups. In buffaloes, the present study is confirmed by the previous report by Alam et al., (2016) in Bangladesh who reported that adults were highly infected than young buffaloes, while the current study contrasts with results by 
Patel et al., (2015) in India who reported than young animals had the highest infection rate. These obtained results might be due to adult animals live for a prolonged period which increases their chance to expose to parasitic infection many times; also neglecting periodical deworming for adult animals might be a reason. In sheep, young animals $(1-3 y)$ had the highest rate of infection, of highly significant importance ( $p<0.01$ ). These findings agree with previous reports by Kakar et al., (2013) in Pakistan, Admasu and Nurlign, (2014), and Elemo and Geresu, (2017) in Ethiopia who stated that young animals were highly infected than adult animals. In contrast, these findings disagree with studies in India by Tramboo et al., (2015) and in Nigeria by Eke et al., (2019) who stated that adult sheep had a high infection rate than young. In goats, young animals of (0-1y) and (1-3y) had the same infection rate and the lowest infection rate was in adult animals $(>3 y)$, of highly significant importance $(\mathrm{p}<0.01)$. The present study is like the previous results by Elemo and Geresu, (2017) in Ethiopia and Eke et al., (2019) in Nigeria who observed that young animals were highly infected than adult ones. The current study disagrees with Ntonifor et al., (2013) in Cameroon and Rashid et al., (2016) in Pakistan who reported that adult animals were highly infected than young ones. The highest infection rate in young animals of sheep and goats might be due to immunity in young animals is low in comparison to adult animals which have a well-developed immune response, also diet changes may affect infection with helminth parasites.

Seasonal prevalence of helminth parasites revealed that the highest infection rate in cattle and sheep was in the winter season, of highly significant difference ( $p<$ 0.01 ). These findings in cattle agree with the previous study by Malathi et al., (2021) who reported that the highest infection rate was in the winter season $(53.64 \%)$, but the current study in contrast to the previous reports by
Kumar et al., (2016) and Shit et al., (2017) in India who found that the highest infection rate was in summer and rainy season, respectively. In sheep, the current study disagrees with two studies in India by Tramboo et al., (2015) who stated that the highest infection rate was in summer season and Dappawar et al., (2018) who found that the highest infection rate was in autumn season. In buffaloes, the highest infection rate was in the summer season, of significant importance $(\mathrm{p}<0.05)$. The present study agrees with Kumar et al., (2016) in India who reported that the highest infection rate was in the summer season, but these findings disagree with shit et al., (2017) in India who reported that the highest infection rate was in the rainy season and Jas et al., (2020) in India who reported that the highest infection rate was in monsoon season. In goats, the highest infection rate was in summer season, but of no significant difference ( $p>0.05$ ) These findings agree with a study by Lone et al., (2012) in India who showed that the highest infection rate was in summer season, but those findings contrast with the previous study by Sutar et al., (2010) in India who observed that the highest infection rate was in rainy season. The differences between the present study and the previous studies might be due to climatic changes as temperature variations, moisture percentage, presence or absence of rain, period of exposure to sunlight.

In the present study, the larval prevalence in cattle after coproculture revealed that the highest percentage of infection was Oesophagostomum radiatum (2.72\%) followed by Cooperia onchophora and Trichostrongylus axei with overall prevalence $(1.8 \%)$ for each species, then $(0.9 \%)$ for infection with Ostertagia ostertagi and Pelodera Strongyloides, of significant importance $(\mathrm{p}<0.05)$. A study in Egypt by Al-Aboody and Omar,(2016) showed that the infection rate of Oesophagostomum spp. , Cooperia spp., Trichostrongylus spp., and Ostertagia spp. 
larvae was (6\%), (49.3\%), (15.6\%) and (26.5\%) respectively, a report by Das and Deka, (2019) in Ethiopia revealed that Oesophagostomum spp., Cooperia spp., and Trichostrongylus spp. were among larvae detected after fecal culture of Strongyle spp. eggs with infection rate $(24.15 \%),(16.1 \%)$, $(19.67 \%)$ and $(0.75 \%)$ respectively, in Indonesia a study by Purwati et al., (2017) revealed that Oesophagostomum spp. , Cooperia spp., Trichostrongylus spp., and Ostertagia spp. among detected nematode larvae with total infection rate $(6 \%),(32 \%)$, $(20 \%)$ and $(4 \%)$ respectively. In buffaloes, the detected species of nematode larvae were Oesophagostomum radiatum and Ostertagia ostertagi with a total infection rate (1.69\%) for each one, of significant importance $(\mathrm{p}<$ 0.05). A study in Pakistan by Zaman et al., (2014) revealed that after coproculture of buffalo's fecal sample, infection rate of Oesophagostomum radiatum and Ostertagia ostertagi larvae was (13\%) and (10.75\%) respectively, in Egypt, Al-Aboody and Omar, (2016) observed that the infection rate of Ostertagia spp. larvae was (34\%), another study by Yadav et al., (2019) in India found that the infection rate of Oesophagostomum spp., and Ostertagia spp. larvae after fecal culture was $(4.26 \%)$ and $(1.1 \%)$ respectively. In sheep, the detected larvae in the present study were Cooperia curticei, Teladorsagia/Ostertagia circumcincta, H.contortus and Strongyloides papillosus with total infection rate $(1.79 \%)$ for each species. A report by Kumsa et al., (2011) in Ethiopia revealed that after coproculture examination, infection rate of Teladorsagia spp, Haemonchus spp., and Strongyloides spp. was (40.3\%), (39.4\%) and (3\%) respectively, Elbahy et al., (2015) in Egypt found that the infection rate of Cooperia curticei, Ostertagia circumcincta, $H$. contortus and S.papillosus larvae was $(2.40 \%),(1.20 \%),(61.44 \%)$ and $(56.62 \%)$ respectively, another study in Egypt by AlAboody and Omar,(2016) observed that the percentage of infection with Cooperia spp., Ostertagia spp., H. contortus and
S.papillosus larvae was (16\%), (30.5\%), $(26 \%)$ and $(37.5 \%)$ respectively. The variation between the present study and the previous studies might be attributed to the sample size, difference in environmental condition, laboratory producers, age, and breed of animals.

\section{Conclusion}

In conclusion, Helminth parasites' diseases remain an important cause of the decrease in the productivity of ruminant animals and many species of helminth parasites eggs and larvae. Additionally, the present study provides baseline data for future researches and studies in ruminant animals.

\section{Acknowledgment}

The authors would like to express their deep thanks to all veterinary doctors who helped in the collection of samples.

\section{Conflicts of interest}

The authors declare that there is no conflict of interest.

\section{References}

Adedipe OD, Uwalaka EC, Akinseye VO, Adediran OA and Cadmus SIB (2014). Gastrointestinal Helminths in Slaughtered Cattle in Ibadan, SouthWestern Nigeria. Journal of Veterinary Medicine, 1-6.

Admasu P and Nurlign L (2014). Prevalence of Gastrointestinal Parasites of Small Ruminants in Kuarit District, North West Ethiopia. African Journal of Basic \& Applied Sciences, 6 (5): 125130.

Ahmad S, Chowdhury MSR, Hossain MM, Rahman MM and Rahman MM (2020). The Prevalence of Gastrointestinal Parasites in Buffalo Calves in Sylhet District of 
Bangladesh. Iranian Journal of

Veterinary Medicine, 14(3): 221-229.

Al-Aboody M S and Omar MA (2016). Prevalence of Gastrointestinal Nematode of Farm Animals by Coproculture. Russian Journal of Parasitology, 36 (2): 168-174.

Alam MR, Erfan R, Sen AB, Das S, Rahman MM and Nath SK (2016). Prevalence of gastrointestinal helminthiasis in naturally infested buffalo in Sylhet district. International Journal of Advanced Multidisciplinary Research, 3(8): 52-58.

Aliyu AA, Maikenti JI, Aimankhu O P, Ayuba SO, Ahmed HO, Haruna A and Idris AM (2020). Helminth Parasites of Goats and Sheep at Slaughter House in Lafia, Nasarawa State, Nigeria. FUDMA Journal of Sciences, 4(2), 34-40.

Anugrah SV, Singh JP, Ramakant NKS and Varun VK (2018).Epidemiology of gastrointestinal parasites in goats of Kumarganj region of Uttar Pradesh. Journal of Pharmacognosy and Phytochemistry, SP4: 16-20.

Aragaw K and Tilahun H (2019). Coprological study of trematode infections and associated host risk factors in cattle during the dry season in and around Bahir Dar, northwest Ethiopia. Veterinary and Animal Science, 7: 1-29.

Awraris T, Bogale B and Chanie M (2012). Occurrence of Gastro Intestinal Nematodes of Cattle in and Around Gondar Town, Amhara Regional State, Ethiopia. Acta Parasitologica Globalis, 3 (2): 28-33.

Bharathi MV and Kumar VN (2017). Epidemiological Studies on Prevalence of Gastrointestinal Parasites in Cattle. Indian Veterinary Journal, 94 (09): 70-72.
Chala D, Alemu B and Diriba S (2019). Prevalence of GastroIntestinal Parasites in Small Ruminants at Tullo District, Western Harerghe Zone, Eastern Ethiopia. European Journal of Biological Sciences, 11 (2): 56-63.

Chikweto A, Tiwari K, Bhaiyat MI, Carloni J, Pashaian K, Pashaian A, De Allie C and Sharma RN (2018). Gastrointestinal parasites in small ruminants from Grenada, West Indies: A coprological survey and a review of necropsy cases. Veterinary Parasitology Regional Studies and Reports, 13: 130-134.

Chowdhury R, Sen A, Kar J and Nath SK (2017). Prevalence of gastrointestinal parasitism of cattle at Chandaniash Upazilla, Chittagong, Bangladesh. International Journal of Advanced Research in Biological Sciences, 4(6): 144-149.

Dappawar MK, Khillare BS, Narladkar BW and Bhangale GN (2018). Prevalence of gastrointestinal parasites in small ruminants in Udgir area of Marathwada. Journal of Entomology and Zoology Students, 6(4): 672-676.

Deeba F, Qureshi AS, Kashif AR and Saleem I (2019). Epidemiology of different gastrointestinal helminths in buffaloes in relation to age, sex and body condition of the host. Journal of Entomology and Zoology Studies, 7(1): 1533-1540.

Eke SS, Omalu ICJ, Ochaguba JE, Urama AC, Hassan SC, Otuu CA and Okafor ID (2019). Prevalence of gastrointestinal parasites of sheep and goats slaughtered in Minna Modern Abattoir, Niger State, Nigeria. Journal of Animal Science and Veterinary Medicine, 4(2):65-70. 
Elbahy NM, Elkhtam AO, AboLaila M and Abdelaziz AR (2015). Microscopic Identification and Seasonal Dynamics of Gastrointestinal Nematodes in Small Ruminants at Menoufia Province. Minufiya Veterinary Journal, 9: 58-65.

Elemo KK and Geresu MA (2017). Prevalence and Risk Factors of Gastro Intestinal Parasites of Small Ruminants in Sinana and Dinsho Districts of Bale Zone, South Eastern Ethiopia. European Journal of Biological Sciences, 9 (1): 1-8.

ELshahawy S, Metwally A and Ibrahim DA (2014). An Abattoir-Based Study on Helminthes of Slaughtered goats (Capra hircus L., 1758) in Upper Egypt, Egypt. Parasitological Institute of SAS, Košice, 51(1): 67-72.

Hamed MI, Abd Ellah MR and Rateb HZ (2013). Helminthiasis: Prevalence and Associated Determinants in Buffaloes Farms in Assiut, Egypt, 19-22 Fabruary. In International Congress of Mediterranean Federation of health and production of ruminants, 95-101.

Haque M, Singh NK, Singh H, Juyal PD and Rath SS (2012). Gastro-Intestinal Parasitism in Dairy Animals of Western Punjab. Indian Veterinary Journal, 89 (9): 20-22.

Hassan NM, Farag TK, El Ezz NMA and Abou-Zeina HA (2019). Prevalence assessment of gastrointestinal parasitic infections among goats in Giza Governorate, Egypt. Bulletin of the National Research Centre, 43(1): 1-7.

Hossain MB, Mahmud MS, Das S, Alim MA, Shaikat AH and Hashem MA (2011). A study on incidence of gastrointestinal parasites in buffaloes from different slaughter houses of Chittagong Metropolitan Area.
University Journal of Zoology, Rajshahi University, 30: 5-7.

Ibrahim N, Tefera M, Bekele $\mathrm{M}$ and Alemu $S$ (2014). Prevalence of Gastrointestinal Parasites of Small Ruminants in and Around Jimma Town, Western Ethiopia. Acta Parasitologica Globalis, 5 (1): 12-18.

Jas R, Kumar D, Pandit S, Baidya S, Brahma A and Rai S (2020). Epidemiology of naturally occurring gastrointestinal helminthoses in buffalo of Coastal zone of West Bengal, India. Journal of Entomology and Zoology Studies, 8(5): 1512-1516.

Jurasek ME, Bishop-Stewart JK, Storey BE, Kaplan RM and Kent ML (2010). Modification and further evaluation of a fluorescein labeled peanut agglutinin test for identification of Haemonchus contortus eggs. Veterinary parasitology, 169(1): 209-213.

Kakar H, Lateef M, Maqbool A, Abdul Jabbar M, Abbas F, Jan S, Abdul Razzaq Kakar E and Shah H (2013). Prevalence and Intensity of Ovine Gastrointestinal Nematodes in Balochistan, Pakistan. Pakistan Journal of Zoology, 45(6): 1669-1677.

Khalafalla RE, Elseify MA and Elbahy NM (2011). Seasonal Prevalence of Gastrointestinal Nematode Parasites of sheep in Northern Region of Nile Delta, Egypt. Parasitology Research, 108: 337-340.

Kumar B, Maharana BR, Prasad A, Joseph JP, Patel B and Patel JS (2016). Seasonal incidence of parasitic diseases in bovines of south western Gujarat (Junagadh), India. Journal of Parasitic Diseases, 40(4): 1342-1346.

Kumsa B, Tedesse T, Sori T, Dugma R and Hussen B (2011). Helminths of Sheep and Goats in Central Oromia 
(Ethiopia) During the Dry Season. Journal of Animal and Veterinary Advances, 10(14): 1845-1849.

Lone BA, Chishti MZ, Ahmad F and Tak H (2012). A Survey of Gastrointestinal Helminth Parasites of Slaughtered Sheep and Goats in Ganderbal, Kashmir. Global Veterinaria, 8 (4): 338-341.

Maharana BR, Kumar B, Sudhakar NR, Behera SK and Patbandha TK (2016). Prevalence of gastrointestinal parasites in bovines in and around Junagadh (Gujarat). Journal of Parasitic Diseases, 40(4): 1174-1178.

Malathi S, Shameem U and Komali M (2021). Prevalence of gastrointestinal helminth parasites in domestic ruminants from Srikakulam district, Andhra Pradesh, India. Journal of Parasitic Diseases, 1-8.

Marskole P, Verma Y, Dixit AK and Swamy M (2016). Prevalence and burden of gastrointestinal parasites in cattle and buffaloes in Jabalpur, India, Veterinary World journal, 9(11): 1214-1217.

Murthy GS and Rao PV (2014). Prevalence of Gastrointestinal Parasites in Ruminants and Poultry in Telangana Region of Andhra Pradesh. Journal of Parasitic Diseases, 38(2):190-192.

Negasi W, Bogale B and Chanie M (2012). Helminth Parasites in Small Ruminants: Prevalence, Species Composition and Associated Risk Factors in and Around Mekelle Town, Northern Ethiopia. European Journal of Biological Sciences, 4 (3): 91-95.

Ntonifor HN, Shei SJ, Ndaleh NW and Mbunkur GN (2013). Epidemiological studies of gastrointestinal parasitic infections in ruminants in Jakiri, Bui Division, North West Region of Cameroon.
Journal of Veterinary Medicine and Animal Health, 5(12): 344-352.

Patel HC, Hasnani JJ, Patel PV, Pandya SS, Solanki JB and Jadav SJ (2015). A study on helminth parasites of buffaloes brought to Ahmedabad slaughter house, Gujarat, India. Life, 50: 20-27.

Ploeger HW, Ankum L, Moll L, Van Doorn DC, Mitchell G, Skuce PJ, Zadoks RN and Holzhauer M (2017). Presence and Species Identity of Rumen Flukes in Cattle and Sheep in the Netherlands. Journal of Veterinary Parasitology, 243: 42-46.

Rashid A, Khattak MNK, Khan MF, Ayaz $S$ and Rehman AU (2016). Gastrointestinal helminthoses: prevalence and associated risk factors in small ruminants of district kohat, pakistan. JAPS, Journal of Animal and Plant Sciences, 26(4): 956-962.

Rashid MM, Hoque MA, Alim MA, Huque KS and Bhuiyan AKFH (2015). Prevalence of gastrointestinal parasites in Brahman crossbred cattle of Bangladesh. Livestock Research for Rural Development, 27 (7): 1-11.

Raza MA, Ayaz MM, Murtaza S and Akhtar MS (2013). Prevalence of GIT Helminths in Cattle at the Vicinities of Tehsil Jatoi, Punjab, Pakistan. Science International (Lahore), 25(2):305-309.

Raza M A, Murtaza S, Bachaya HA, Abdul Q and Zaman MA (2010). Point Prevalence of Toxocara vitulorum in Large Ruminants Slaughtered at Multan Abattoir. Pakistan Veterinary Journal, 30(4): 242-244.

Saha SS, Bhowmik DR and Chowdhury MMR (2013). Prevalence of Gastrointestinal Helminthes in Buffaloes in Barisal District 
Bangladesh. Bangladesh Journal of Veterinary Medicine, 11(2): 131-135.

Shit N, Hajra DK, Baidya S and Debbarma A (2017). Seasonal Occurrence of Gastrointestinal Helminth Parasites in Cattle and Buffaloes in Bankura District, West Bengal, India. Exploratory Animal and Medical Research, 7(1): 58-63.

Sultan K, Desoukey AY, Elsiefy MA and Elbahy NM (2010). An Abattoir Study on the Prevalence of Some Gastrointestinal Helminths of Sheep in Gharbia Governorate, Egypt. Global Veterinaria, 5 (2): 84-87.

Sultan, K.; Elmonir, W. and Hegazy, Y. (2016): Gastrointestinal Parasites of Sheep in Kafrelsheikh Governorate, Egypt: Prevalence, Control and Public Health Implications. Beni-suef University Journal of Basic and Applied sciences, 5: 79-84.

Sunday ES, Amarachi NF, James OIC, Agha OC, Oghenebukome OJ, Ochigbo UE and Kolawole KI (2020). Gastrointestinal Helminths Infections in Small Ruminants Slaughtered in Minna Modern Abattoir, North Central, Nigeria. Journal of Animal and Veterinary Sciences, 7(3): 13-18.

Sutar AU, Kengar SB, Patil SS and Khan MR (2010). Prevalence of Gastrointestinal Parasites in Goats of Ahmednagar District of Maharashtra. Veterinary World, 3(10): 456-457.

Tramboo SR, Shahardar RA, Allaie IM, Wani ZA and Bushra MS (2015). Prevalence of Gastrointestinal helminth Infections in Ovine Population of Kashmir Valley, Veterinary World, 8(10): 1199-1204.
Tulu D and Lelisa K (2016). A Study on Major Gastro-Intestinal Helminths Parasites of Cattle in Tulo District, West Hararghe Zone, South-Eastern Ethiopia. Austin Journal of Veterinary Science \& Animal Husbandry, 3(2): 36.

Umar YA, Babayo SA and Mao PS (2018). Gastrointestinal Helminths of Slaughtered Cattle in Bauchi Central Abattoir, Bauchi State, Nigeria. GSC Biological and Pharmaceutical Sciences, 04(02): 58- 65.

van Wyk, J. A.; Cabaret, J. and Michael, L. M. (2004): Morphological Identification of Nematode Larvae of Small Ruminants and Cattle Simplified. Veterinary Parasitology, 119(4): 277-306.

van Wyk JA and Mayhew E (2013). Morphological Identification of Parasitic Nematode Infective Larvae of Small Ruminants and Cattle: A practical lab guide. A practical lab guide, Onderstepoort Journal of Veterinary Research, 80(1): 1-14.

Yohanna JA, Dung GK, Adejoh VA and Pam DD (2019).Prevalence of Helminth Parasites of Ruminants in Abattoir Market Jos, Jos South Local Government Area, Plateau State, Nigeria. International Journal of Biomedical and Health Sciences, 15(2): 51-57.

Zaman M A, Sajid M, Sikandar A and Awais MM (2014). Point Prevalence of Gastrointestinal Helminths and their Association with Sex and Age of Buffaloes in Lower Punjab, Pakistan. International Journal of Agriculture \& Biology, 16(6): 1229-1231. 